Historic, Archive Document

Do not assume content reflects current scientific knowledge, policies, or practices. 


\section{THE HARRY N. HAMMOND SEED CO,}

BAY CITY, MICH.

February I, 1901.

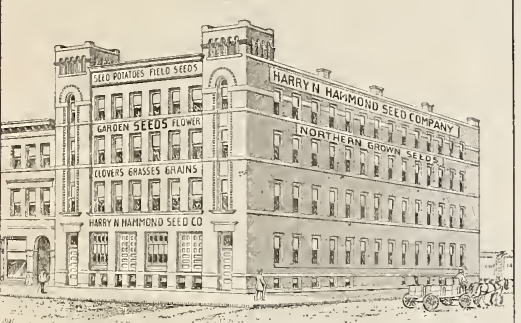

We offer following surplus stocks, all crops 1900, F. O. B. Bay City. Bags extra at value. Terms, cash by draft against bill lading subject to inspection. Note low prices Peas and Beans to close out.

Peas and Beans carefully grown and well hand-picked stocks.

Prices quoted are for prompt order subject to being unsold.

REMEMBER WE CAN ONLY OFFER SEEDS CROP OF 1900.

SAMPLES FREE ON REQUEST.

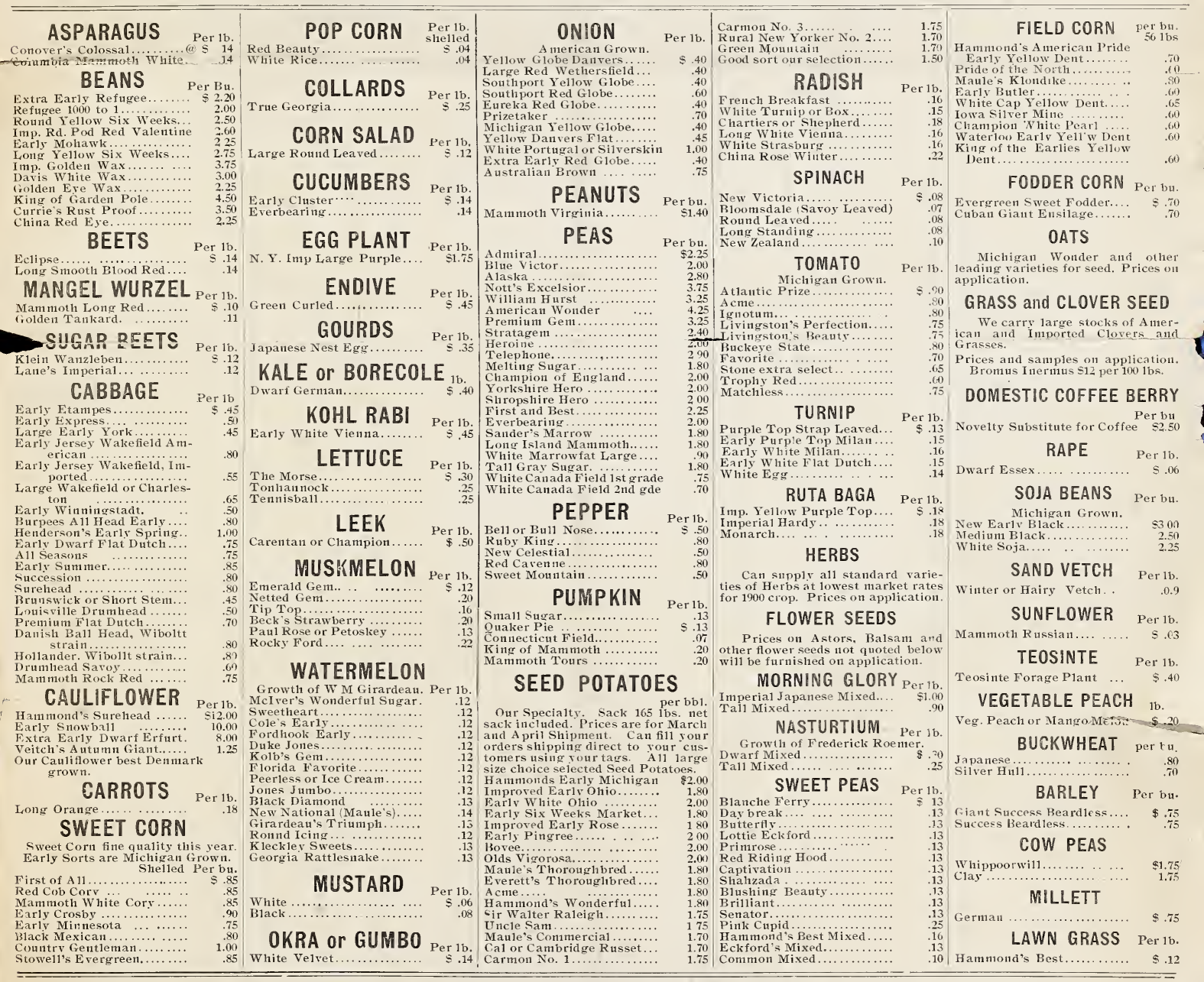


CIEE $=Y$ RECGITVD * JUL 191923 ћ

T. S. Department of Agrioultomer.

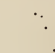

